ty and other benefits in CHF. The omission of betal receptor antagonists is especially disappointing given the recent findings of the Metoprolol CR/XL Randomized Intervention Trial in Heart Failure (MERIT-HF) as well as recently published results of the CIBIS II trial. MERIT-HF is the largest heart failure trial evaluating a beta blocker ever completed. The results of MERIT-HF were announced on November 11, 1998, at the 71st Scientific Sessions of the American Heart Association, and at the recent meeting of the American College of Cardiology mentioned in the commentary. In patients with congestive heart failure, the addition of Toprol XL ${ }^{\ominus}$ (metoprolol succinate) to standard treatment was shown to improve survival and reduce all-cause mortality by approximately $35 \%$. This trial was discontinued early, on October 31, 1998, at the recommendation of the Independent Safety Committee when it became clear that patients treated with Toprol XL were experiencing a large survival benefit over those treated with placebo. The significance of these trials (MERIT-HF and CIBIS II) is obvious. It provides a welcome addition to the growing body of evidence that beta 1 -selective blockers are beneficial in the treatment of congestive heart failure.

$$
\begin{array}{r}
\text { Michael Klibaner, M.D., Ph.D. } \\
\text { Director, Clinical Research } \\
\text { Cardiovascular Therapeutic Team } \\
\text { Astra Pharmaceuticals } \\
\text { Wayne, Pennsylvania }
\end{array}
$$

\section{Clinical Implications of Endothelial Dysfunction}

\section{J. Pepine: Clin Cardiol 1998;21:795-799}

\section{To the Editor:}

I read with interest the review on endothelial dysfunction by Dr. Pepine, although I believe one area of particular importance to the practicing clinician that was not mentioned in the article should be noted. Several recent reports have highlighted the role of estrogen in reversing endothelial dysfunction in postmenopausal women., ${ }^{1,2}$ Roque $e t$ al. ${ }^{1}$ showed that $24 \mathrm{~h}$ of transdermal estradiol significantly improved acetylcholine-induced vasoreactivity. The longer term putative effects of estrogen on endothelial function were demonstrated by Bush $e t ~ a l .^{2}$ by assessing postischemic vasodilation in postmenopausal women prior to beginning hormone replacement therapy and 6 months thereafter. The recently reported HERS trial, ${ }^{3}$ a prospective trial of hormone replacement therapy for secondary prevention of ischemic heart disease, did not show a striking benefit in the clinical realm. This may be due to a deleterious effect of progesterone, a necessary evil in many patients with an intact uterus. Nevertheless, estrogen seems to have a beneficial effect on endothelial function, and is fre- quently indicated for other reasons in the postmenopausal patient. Its use should be considered when treating a postmenopausal patient with endothelial dysfunction.

\author{
James L. Furgerson, M.D. \\ Cardiology Service \\ Brooke Army Medical Center \\ Fort Sam Houston, Texas
}

\section{References}

1. Roque M, Heras M, Roig E, Masotti M, Rigol M, Bertriu A, Balasch J, Sanz G: Short-term effects of transdermal estrogen replacement therapy on coronary vascular reactivity in postmenopausal women with angina pectoris and normal results on coronary angiograms. J Am Coll Cardiol 1998;31(1):139-143

2. Bush DE, Jones CE, Bass KM, Walters GK, Bruza JM, Ouyang P: Estrogen replacement reverses endothelial dysfunction in post menopausal women. Am J Med 1998;104:552-558

3. Hulley S, Grady D, Bush T, Furberg C, Herrington D, Riggs B, Vittinghoff E: Randomized trial of estrogen plus progestin for secondary prevention of coronary heart disease in postmenopausal women. Heart and Estrogen/progestin Replacement Study (HERS) Research Group. J Am Med Assoc 1998;280:605-613

\section{Aortic Stenosis}

I. E. Godoy and R. M. Lang: Clin Cardiol 1998;21:845

\section{To the Editor:}

In "Aortic Stenosis" by Godoy and Lang, the authors refer to a diamond-shaped systolic murmur. I doubt that anyone could hear a decrescendo part of a systolic murmur of aortic stenosis, although this, of course, could be demonstrated in the phonocardiogram. If one does hear a decrescendo murmur, it is more likely due to concomitant aortic regurgitation.

\section{Martin N. Frank, D.D., F.A.C.P., F.A.C.C. Abington Medical Specialists Abington, Pennsylvania}

\section{Author's reply:}

It is possible that Dr. Frank is correct in suggesting that the decrescendo portion of the systolic ejection murmur of aortic stenosis that we described was indeed a murmur of concomitant aortic regurgitation. This patient indeed also had mild aortic regurgitation.

Roberto M. Lang, M.D. The University of Chicago Medical Center Chicago, Illinois 